\title{
EDITORIAL
}

\section{PROFISSIONALIZAÇÃO DOS PERIÓDICOS: NOVAMENTE}

A área de Educação Física/Ciências do Esporte vem enfrentando importantes discussões sobre seus periódicos. $\bigcirc$ qualis da área, que tem sofrido decisivas alterações nos últimos tempos, os critérios de avaliação e publicação de artigos, a periodicidade, a internacionalização, entre tantos outros temas, são debatidos no contexto das questões próprias da pesquisa e produção do conhecimento. As revistas não podem ser analisadas isoladamente, mas como expressão do movimento área em suas diversas dimensões. Tudo o que afeta os periódicos, incluindo sua própria existência e desenvolvimento, diz respeito, por exemplo, ao sistema de pós-graduação.

É muito importante que a Educação Física/Ciências do Esporte siga discutindo as questões pertinentes à produção e difusão do conhecimento e que, no interior desse intercâmbio de ideias e busca de soluções, aborde o problema da profissionalização do processo de gestão dos periódicos. A simples sobrevivência de nossas publicações é uma questão ainda não resolvida, dependentes que somos de recursos incertos e sazonais. Este tema, já abordado em outros editoriais, precisa ser enfrentado sem medos ou preconceitos. Ou as revistas se profissionalizam e deixam de viver à custa da dedicação de alguns, ou elas, e a área como um todo, seguirão com dificuldades em avançar.

Esses assuntos foram apresentados por nós em recente evento que comemorava os vinte anos da Revista Movimento, da Escola de Educação Física da Universidade Federal do Rio Grande do Sul. Diferentemente da RBCE, a Movimento é 
uma publicação com corte temático nas Ciências Humanas e Sociais. É ótimo para a área de Educação Física/Ciências do Esporte que haja periódicos como a Movimento e com sua longevidade, sinal de consolidação e respeito entre os pares. Ou como a Revista de Educação Física/UEM, recentemente incorporada à base SciELO. A esses dois periódicos, nossas congratulações.

Este número da RBCE forma-se com temas variados, como é costumeiro, mas com artigos que eventualmente compõem blocos temáticos. Um desses blocos é o que abre o número, com quatro artigos de abordagem historiográfica. Abordando distintos temas emoldurados por diferentes periodizações, tratam dos Jogos Olímpicos de Saint Louis, do primeiro recordista brasileiro do lançamento de dardo, da constituiçã̃o do subcampo do xadrez, de representações dos corpos infantis na revista Pais \& Filhos. A trajetória de um clube de futebol no Campeonato Brasileiro de 2009, a partir de charges jornalísticas, é tema do quinto trabalho, antecedendo os quatro artigos sobre jogo, que compõe o segundo bloco temático. Dois deles referem-se ao tema no espaço escolar, o seguinte enraíza-se no debate dos meios de comunicação, o último dedica-se à capoeira. Idosos são os sujeitos estudados pela pesquisa que dá origem ao artigo a seguir. Skatistas e adultos com excesso de peso aparecem nos trabalhos seguintes, elaborados a partir de investigações com aporte na biodinâmica do exercício físico. Jogadores de Handebol e de Goalball também encontram seus espaços nas contribuições que publicamos neste número, assim como as condições de participação de crianças e jovens em um projeto sócio-educativo.

Entre os quinze artigos originais desta edição, dois são de colegas de outros países, nomeadamente da França e da Argentina. Um terceiro, de um grupo do Brasil, é publicado em inglês. Todo esse movimento aponta para o prosseguimento da internacionalização da RBCE e da área como um todo: publicamos trabalhos de pesquisadores estrangeiros, dialogamos com eles por meio dos nossos.

Por fim, apresentamos um artigo de revisão e uma resenha, dois importantes produtos, além dos artigos originais, para o processo de reconhecimento e debate interno na Educação Física/Ciências do Esporte.

Boa leitura!

Florianópolis, Vitória, setembro de 2012.

Alexandre Fernandez Vaz

Felipe Quintão de Almeida

Jaison José Bassani 